UDC 538.9

A.M. Alieva*

\title{
PHOTOCONDUCTIVITY AND LUMINESCENCE OF GASE CRYSTALS AND NANOPARTICLES AT HIGH LEVELS OF OPTICAL EXCITATION
}

It has been shown that GaSe nanoparticles possess high photosensitivity in the $0.34 \div 1.40 \mathrm{eV}$ spectral range at room temperature. Photoconductivity and photoluminescence in GaSe layered crystals are experimentally investigated for high levels of optical excitation. Observed features of photoconductivity and photoluminescence spectra are determined by nonlinear optical absorption in the range of exciton resonance.

Keywords: photoconductivity, photoluminescence, nanoparticles, laser, GaSe.

*Alieva Aytan Movsum gizi - senior Researcher, Institute of Physics, National Academy of Sciences of Azerbaijan, Azerbaijan.

doi: 10.15350/2221-2345.2017.1-2.6-12

УДК 538.9

А.М. Алиева*

\section{ФОТОПРОВОДИМОСТЬ И ЛЮМИНЕСЦЕНЦИЯ КРИСТАЛЛОВ И НАНОЧАСТИЦ GASЕ ПРИ ВЫСОКИХ УРОВНЯХ ОПТИЧЕСКОГО ВОЗБУЖДЕНИЯ}

Показано, что наночастицы GaSe обладают высокой фоточувствительностью в спектральной области $0,34 \div 1,40 \ni$ В при комнатной температуре. Экспериментально исследована фотопроводимость и люминесценция в слоистых кристаллах GaSe при высоких уровнях оптического возбуждения. Наблюдаемые особенности спектров фотопроводимости и люминесценции определяются нелинейным оптическим поглощением в области экситонного резонанса.

Ключевые слова: фотопроводимость, фотолюминесценцию, наночастицы, лазер, GaSe.

*Алиева Айтан Мовсум гызы - старший научный сотрудник, Институт физики Национальной академии наук Азербайджана, Азербайджан.

Исследования размерных квантовых явлений в малоизученных и в тоже время перспективных слоистых полупроводниках $\mathrm{A}^{3} \mathrm{~B}^{6}$ открывают большие перспективы для конструирования на их основе новых элементов с широким спектром функциональных возможностей. Ионно-ковалентная связь между атомами в слоях и слабое ван-дер-ваальсовское взаимодействие между ними обуславливают сильную анизотропию их физических свойств и являются основной причиной наблюдения ряда эффектов, несвойственных другим анизотропным полупроводникам. С другой стороны, благодаря малой плотности оборванных связей на поверхности скола (менее $10^{10} \mathrm{~cm}^{-2}$ ), слоистые полупроводники могут использоваться в качестве подложек для формирования квантовых точек, выращивания фуллеров, полимеров, а также для ван-дерваальсовой эпитаксии [1-7]. Фотоприемники видимого, ультрафиолетового и ближнего ИКдиапазонов спектра на основе слоистых кристаллов выгодно отличаются высокой радиационной стойкостью, повышенной фоточувствительностью и быстродействием. Благодаря большой 
нелинейной восприимчивости, эти соединения обладают нелинейно-оптическими свойствами, и в них обнаружены такие эффекты, как генерация второй гармоники, двухфотонное поглощение, параметрическая генерация света, оптическая бистабильность, генерация лазерного излучения и т.д. [8-11].

Проведенный теоретический анализ на примере GaSe показал, что из термодинамических соображений возможно существование нанотрубок радиусом 40-48A $\mathrm{A}^{0}$. Позднее для GaSe они были получены путем лазерного и термически индуцированного отслоения. Известно также о получении нанотрубок GaSe путем испарения и эксфолиации органикой или через механизм роста пар-жидкость-твердая фаза в ходе термического испарения GaSe при использовании наночастиц золота как катализатора. Что же касается наночастиц (квантовых точек), то для их получения был использован ряд методов высокотемпературного химического синтеза. При этом D.F. Kelley, V. Chikan получили наночастицы GaSe, имеющие форму диска диаметром 2-6 нм и толщиной в четыре моноатомных слоя (Se-Ga-Ga-Se) [2].

Ранее нами в кристаллах GaSe экспериментально исследовалось нелинейное поглощение света в области экситонного резонанса при высоких интенсивностях оптического возбуждения [12]. Было показано, что наблюдаемая временная зависимость коэффициента поглощения и его зависимость от интенсивности возбуждения определяются не только экситон-экситонным взаимодействием и экранированием экситонов плазмой неравновесных носителей, но и характером протекания явлений, связанных с кинетическими и релаксационно-рекомбинационными процессами в этих системах.

Большинство работ, посвященных фотопроводимость (ФП) в $\mathrm{GaSe}$, были проведены с использованием обычных (не лазерных) источников света при низких интенсивностях возбуждения.

В данной работе экспериментально исследуются фотопроводимость кристаллов $\mathrm{GaSe}$ при высоких уровнях оптического возбуждения и экспериментальные результаты получения наночастиц на основе кристаллов $\mathrm{GaSe}$, анализ их структуры и исследования спектров поглощения, фотопроводимости и люминесценции.

Наночастицы GaSe были получены методом дробления прибором «Pulverisette» в течение 150 часов в непрерывном режиме работы. Спектры поглощения и фотолюминесценции были измерены с помощью монохроматора JOBIN-YVON с дифракционной решеткой с последующим детектированием ФЭУ100. Выход сигналов подавался в нестационарную цифровую систему (transient dijitizer system), которая включала запоминающий осциллограф (Le Groy 9400) и компьютерную систему (board Master 800 ABI 8).

Для измерения фоточувствительности наночастиц GaSe были изготовлены специальные образцы. Наночастицы клали в изотропиловый спирт, перемешивали стеклянной палочкой. Образовывалась суспензия мелких частиц порошка. Более тяжелые и слипшиеся частицы оседали на дно сосуда. Суспензию переливали в другой сосуд. С помощью стеклянной пипетки, суспензию капали на ситалловую подложку. Спирт испарялся, на подложку оседал слой порошка. Получившийся таким образом слой порошка имел толщину $\leq 50$ мкм. Образец подвергался отжигу в вакууме, при $\mathrm{T}=750 \mathrm{~K}$ в течение 4 часов. На образец наносились контакты серебряной (Ag) пастой.

Электроды наносились в планарной конфигурации. Освещение образца монохроматическим светом для измерения фотопроводимости, проводилось с помощью монохроматора «VSU 2-р» фирмы «CARLZEISS». В качестве источника света использовалась ксеноновая лампа высокого давления ДКСШ-150. Ток через образец измерялся с помощью усилителя постоянного тока «У5-9». Ток с выхода усилителя отображался на цифровом универсальном вольтметре В621, а также рисовался на двухкоординатном самописце-потенциометре «ENDIM 620.02»

На Рис. 1 приведен спектр фотопроводимости наночастиц GaSe. Как видно из рисунка, фоточувствительность наночастиц охватывает диапазон спектра в области $0,35 \div 1,4$ мкм. Основной максимум спектра соответствует 0,6 мкм, который связан с краем полосы поглощения массивных образцов 


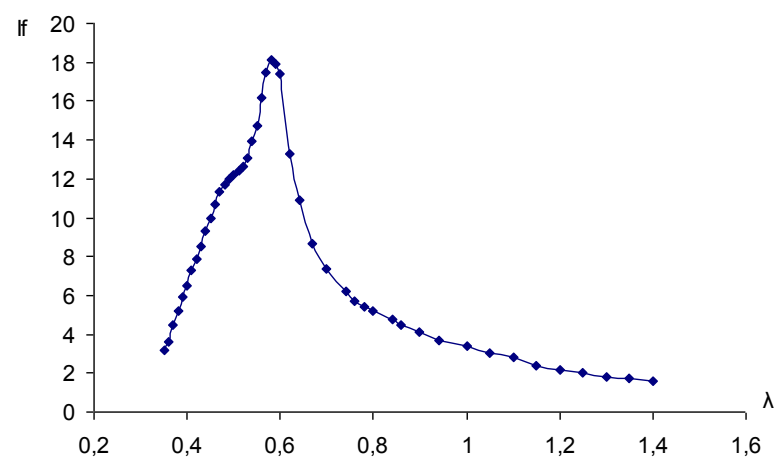

Рис. 1. Спектры фотопроводимости наночастиц $\mathrm{GaSe}$

Кроме этого максимума в коротковолновой области спектра наблюдается еще один пик $(\lambda \approx 430$ нм). По нашему мнению, этот пик, как в спектрах поглощения и люминесценции, обусловлен наночастицами GaSe. Наличие фоточувствительности образцов в широком диапазоне свидетельствует о том, что наночастицы обладают различными размерами.

Исследования спектров фотолюминесценции GaSe показали, что если для кристаллов $\mathrm{GaSe}$ наблюдаются характерные линии краевой $(\lambda=660 \mathrm{Hм})$ и примесной $(\lambda=800 \mathrm{Hм})$ люминесценции, или же в некоторых кристаллов только примесной ( $\lambda=800$ нм) люминесценции, то для наночастиц, как и в случае спектре поглощения, наблюдается коротковолновая люминесценция с максимумом $\lambda=430$ нм (Рис. 2). Сдвиг максимума люминесценции в сторону длинных волн по сравнению со спектром поглощения, по-видимому, обусловлен стоксовым смещением.

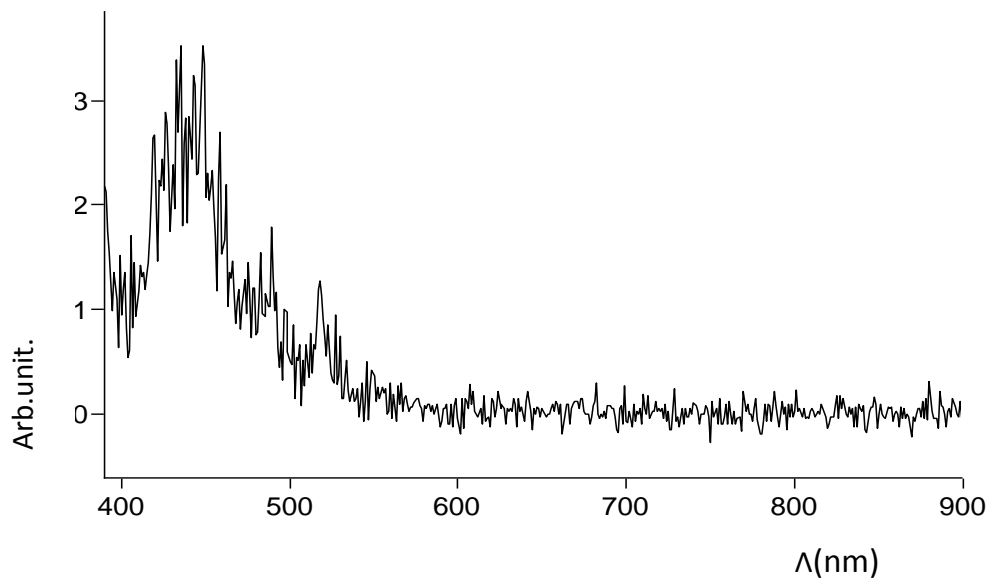

Рис. 2. Спектры фотолюминесценции наночастиц GaSe

\section{Образиы и методика эксперимента}

Исследования проводились на специально не лигированных кристаллах p-GaSe, выращенных методом Бриджмена. Образцы с толщинами 100-300 мкм, площадью 1 $\mathrm{cm}^{2}$ были изготовлены из крупных слитков путем скалывания перпендикулярно кристаллографической оси с. На свежесколотую поверхность образца методом термического испарения в вакууме был нанесен омический контакт In. Согласно холловским измерениям, удельное сопротивление, концентрация и подвижность носителей тока составляли $\rho=10^{3}-10^{5} \mathrm{OM}^{\cdot} \mathrm{cm}, \mathrm{p}=4 \cdot 10^{14} \mathrm{~cm}^{-3}$ и $\mu$ $\approx 20 \mathrm{~cm}^{2} /(\mathrm{B} \cdot \mathrm{c})$ соответственно. Кристаллы $\mathrm{GaSe}$ облучались импульсами жидкостного лазера PRA, LN-107 (активная среда - родамин 6G), накачку которого осуществляли азотным лазером PRA, LN-1000. Область перестройки длины волны излучения лазера 594-643нм полностью перекрывает край полосы фундаментального поглощения GaSe (ширина запрещенной зоны $\mathrm{Eg}$ $=2.02 э \mathrm{~B}$ при температуре $\mathrm{T}=300 \mathrm{~K})$. Ширина линии генерации лазерного излучения во всем 


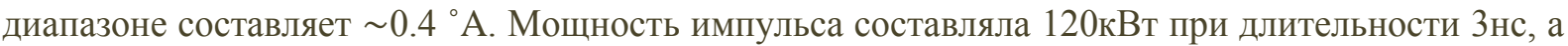
частота повторения импульса равнялась 20Гц. Интенсивность лазерного излучения варьировалась при помощи калиброванных нейтральных фильтров. При измерении фотопроводимости луч лазера направляли перпендикулярно поверхности образца (параллельно оси с) и фокусировали в пятно диаметром 0.1мм. Были предприняты специальные меры, чтобы на контакты не падало лазерное излучение. К образцу прикладывали внешнее электрическое поле 1-100В/см. В этом интервале фототок изменялся практически линейно с полем. Длительность лазерного луча оказалась меньше, чем время релаксации носителей тока, поэтому за время импульса не устанавливалась стационарная фотопроводимость. При измерении фотолюминесценции излучение лазера направлялось на сколотую поверхность кристалла под углом 20॰ к нормали, а фотолюминесценция наблюдалась в направлении, перпендикулярном к поверхности. Регистрация фотолюминесценции производилась с помощью монохроматора JOBIN-YVON с дифракционной решеткой и последующим детектированием фотоумножителем ФЭУ-100. Сигнал ФП или ФЛ подавался в нестационарную цифровую систему (transient digitizer system), которая включала запоминающий осциллограф (Le Groy 9400) и компьютерную систему (board Master 800 ABI 8).

\section{Экспериментальные результаты и обсуждение}

На рис. 3 представлены спектры ФП $(\Delta \sigma)$ кристаллов $\mathrm{GaSe}$ при различных интенсивностях $\left(\mathrm{I}_{0}\right)$ оптического возбуждения. При низких мощностях накачки наблюдается хорошо известная экситонная ФП с максимумом при энергии фотона $h v \approx 2.00$ э. С ростом мощности накачки увеличивается концентрация фотоносителей, что приводит к увеличению ФП в экситонной области (кривая 2). Дальнейшее увеличение интенсивности возбуждения приводит к уширению и исчезновению экситонного пика (кривые 3,4$)$, но при этом ФП за краем фундаментального поглощения резко возрастает.

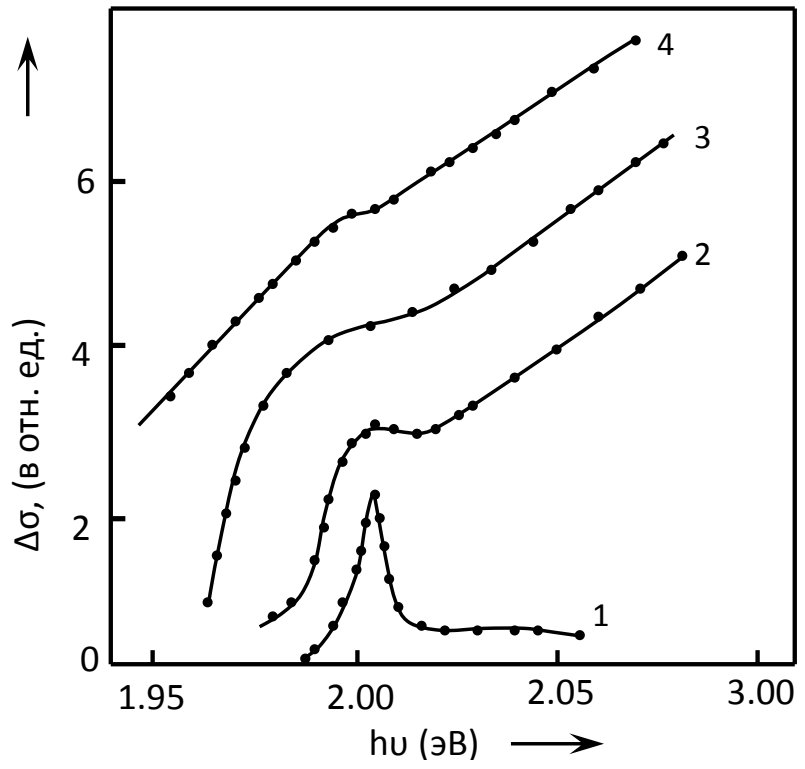

Рис. 3. Спектры фотопроводимости кристаллов GaSe при различных интенсивностях возбуждения, МВт/см2:1 - 0.46,2 - 2.28, 3-6.14, 4-12.

Спектры ФЛ GaSe при различных интенсивностях возбуждения представлены на рис. 4. Как видно из рисунка, эти спектры кроме линии свободного экситона (FE, длина волны $\lambda=$ 591нм при 80K) содержат также низкоэнергетическую полосу (L-полоса). При низких уровнях возбуждения в спектре присутствует только линия излучения свободного экситона FE (кривая $1)$, но с ростом мощности накачки $\left(\mathrm{I}_{0}>0.8 \mathrm{MBT} / \mathrm{cm}^{2}\right)$ в длинноволновой области спектра, на 20мэВ ниже линии излучения свободного экситона, 


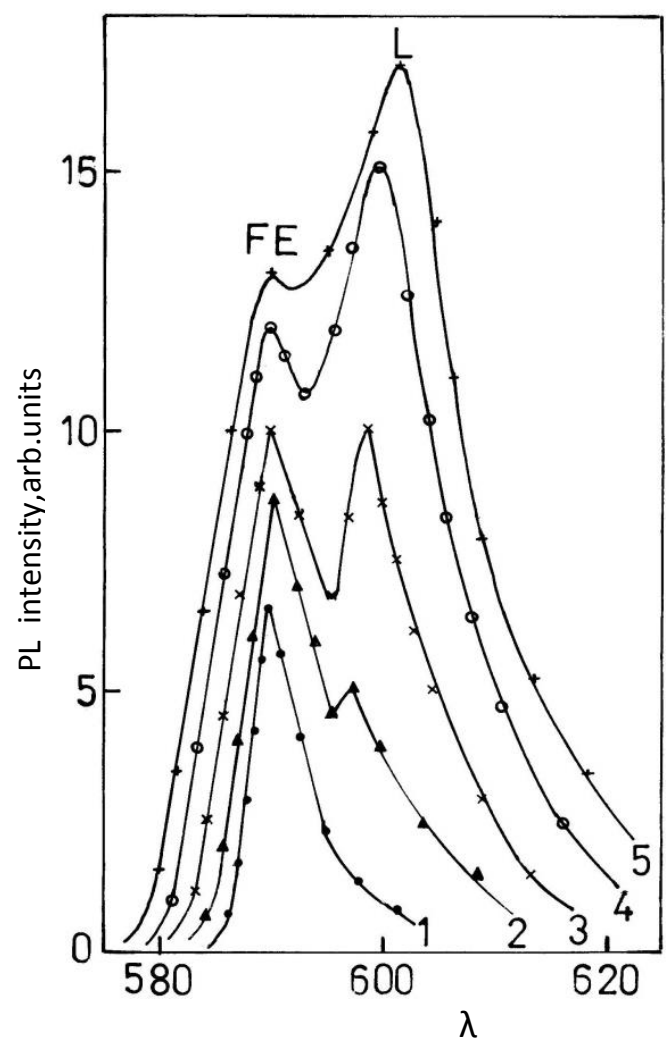

Wavelength, nm

Рис. 4. Спектры фотолюминесценции (PL) кристаллов GaSe при различных интенсивностях возбуждения, МВт/см²: $1-0.12,2-1.01,3-4.02,4-6.03,5-12 . \mathrm{T}=80 \mathrm{~K}$

появляется полоса излучения с максимумом при $\lambda=597$ нм. При очень высоких уровнях возбуждения в спектре излучения доминирует L-полоса люминесценции. Следует отметить, что в зависимости от интенсивности возбуждения положение L-полосы меняется, наблюдается ее смещение в сторону длинных волн. Наблюдаемые особенности в спектрах ФП и ФЛ кристаллов $\mathrm{GaSe}$ при высоких уровнях оптического возбуждения, по-видимому, могут быть объяснены нелинейным поглощением света в области экситонного резонанса. Действительно, при возбуждении кристаллов $\mathrm{GaSe}$ лазерным светом электроны и дырки связываются в экситоны. В дальнейшем, с увеличением интенсивности возбуждения, концентрация экситонов растет и при до стижении некоторого критического значения концентрации происходит взаимодействие между экситонами, что приводит к распаду экситонов и образованию свободных электроннодырочных пар [12]. Оценки показывают, что плотность генерированных электронно-дырочных пар в $\mathrm{GaSe}$ при мощности накачки $\sim 10 \mathrm{MB} / \mathrm{cm}^{2}$ составляет $4.5 \cdot 10^{19} \mathrm{~cm}^{-3}$, что значительно превышает плотность, необходимую для моттовского перехода в GaSe, равную $\mathrm{nMott}=1 \cdot 10^{17} \mathrm{~cm}^{-3}$ [18]. Анализ кинетических уравнений ФП в GaSe показывает, что при низких уровнях возбуждения ФП линейно изменяется с интенсивностью возбуждения, но при высоком уровне возбуждения, когда экситон-экситонное взаимодействие становится доминирующим, линейная зависимость превращается в сублинейную. Наши экспериментальные результаты по ФП в $\mathrm{GaSe}$ находятся в хорошем согласии с результатами работ [19] до уровня возбуждения $3 \mathrm{MBT} / \mathrm{cm}^{2}$, но для более высоких уровней возбуждения ФП начинает уменьшаться. Уменьшение ФП при более высоких уровнях возбуждения $\left(>4 \mathrm{MB} / \mathrm{cm}^{2}\right)$ может быть объяснено не только уменьшением экситонного поглощения, обусловленным процессом экситон-экситонного взаимодействия, но также уменьшением рекомбинационного времени жизни электронно-дырочных пар, связанным 
с другими процессами, такими как двухфотонное поглощение, поглощение свободными носителями заряда и т.д.

В пользу влияния нелинейного поглощения на ФП кристаллов GaSe также свидетельствует построенная нами зависимость $\alpha \cdot \mathrm{I}_{0}$ от $\mathrm{I}_{0}$ характеризующая ФП неравновесных носителей тока. При этом в качестве коэффициента оптического поглощения $\alpha$ были взяты значения, измеренные при разных интенсивностях лазерного излучения [12]. Сравнение кривых $\alpha \mathrm{I}_{0}=\mathrm{f}\left(\mathrm{I}_{0}\right)$ с экспериментально измеренными кривыми $\Delta \sigma=\mathrm{f}\left(\mathrm{I}_{0}\right)$ показало, что зависимости имеют схожий вид.

Что касается природы L-полосы, наблюдаемой в спектрах люминесценции исследованных кристаллов $\mathrm{GaSe}$, то она не может быть объяснена примесным излучением, излучением связанных экситонов, а также фоннонным повторением свободных экситонов. Связь L-полосы с излучением экситонной молекулы также является маловероятной, так как это излучение обычно появляется на 6мэВ ниже линии свободного экситона, поэтому не может быть обнаружено экспериментально при 80K. Одними из наиболее возможных причин появления L-полосы могут быть процессы соударения, такие как экситон-электронное или экситон-экситонное, которые имеют место при высоких уровнях оптического возбуждения. Наши экспериментальные результаты свидетельствуют в пользу экситон-экситонного взаимодействия. При экситонэкситонном взаимодействии энергия излучаемого кванта $\mathrm{h} v$ на $2 \mathrm{E}_{\mathrm{b}}$ меньше ширины запрещенной зоны $\mathrm{Eg}[20]$, поэтому

$$
\mathrm{h} v=\mathrm{E}_{\mathrm{g}}-2 \mathrm{E}_{\mathrm{b}}-\Delta \mathrm{E}
$$

где $\mathrm{E}_{\mathrm{b}}$ - энергия связи экситона

$$
\Delta E=\frac{1}{\mu} \frac{h^{2}}{8}\left(\frac{3}{8 \pi}\right)^{2 / 3}\left(\frac{N}{V}\right)^{2 / 3}
$$

Здесь N/V - темп генерации свободных носителей в единице объема, $\mu=\left(\frac{1}{m_{e}}+\frac{1}{m_{h}}\right)^{-1}$

- приведенная эффективная масса электронно-дырочных пар.

Оценки $\Delta \mathrm{E}$ по формуле (2) показывают, что при значении $\mathrm{m}_{\mathrm{e}}=0,7 \mathrm{~m}_{0}, \mathrm{~m}_{\mathrm{h}}=0,5 \mathrm{~m}_{0}$ и $\mathrm{I}_{0}=10$ $\mathrm{MBT} / \mathrm{cm}^{2}, \Delta \mathrm{E}$ для $\mathrm{GaSe}$ составляет $\sim 15 \mathrm{M} \ni$, что сравнимо с экспериментально найденными значениями.

Итак, на основании вышеизложенного можно утверждать, что новая полоса люминесценции, наблюдавшаяся в GaSe при высоких уровнях оптического возбуждения, обусловлена экситон-экситонным взаимодействием.

\section{Заключение}

Спектры фотопроводимости и фотолюминесценции кристаллов $\mathrm{GaSe}$ при низких уровнях возбуждения содержат только линии поглощения, обусловленные свободными экситонами. С ростом интенсивности возбуждения экситонный пик исчезает и появляется новая полоса излучения, находящаяся на расстоянии от линии свободного экситона на 20мэВ. Наблюдаемые особенности объясняются на основе нелинейного поглощения света, обусловленного экситонэкситонным взаимодействием.

\section{Библиографический список:}

[1] Michel Cote, Marvin L.Cohen, D.L.Chadi, Phys. Rev., B 58 (1998) 4277.

[2] H.Tu.S.Yang, V.Chikan, D.F.Kelley, J. Phys. Chem., B 108 (2004) 4701. 
[3] Xiang-Bai Chen, David F.Kelley, J. Phys. Chem., B 110 (2005) 25259.

[4] M.B.Muradov, G.M.Eyvazova, Y.M.Yolchiev, N.G.Darvishov, Int. Conf. Technical and Physical Problems in Power Engineering, Ankara, (2006) 665.

[5] А.П.Бахтинов, З.Д.Ковалюк, О.Н.Сидор и др., ФТТ, 49 (2007) 1498.

[6] С.И.Драпак, З.Д.Ковалюк, ФТП, 41 (2007) 312.

[7] F.Kh.Mirzade, K.R.Allakhverdiev, Z.Yu.Salayeva, J. Nanoscience and Nanotechnology, 8 (2008) 764.

[8] M.Caraman, E.Cuculescu, I.Evtodiev, J. of Optoelectronocs and Advanced Materials, 7 (2005) 805.

[9] А.Г.Кязым-заде, А.А.Агаева, В.М.Салманов, А.Г.Мохтари, Неорганические Материалы, 43 (2007) 1419.

[10] А.Г.Кязым-заде, А.А.Агаева, В.М.Салманов, А.Г.Мохтари, ЖТФ, 77. (2007) 80.

[11] А.Г.Кязым-заде, В.М.Салманов, А.А.Салманова, А.М.Алиева, Р.З.Ибаева, ФТП, 44 (2010) 306.

[12] А.Г. Кязым-заде, А.А. Агаева, В.М. Салманов, А.Г. Мохтари. Неорг. матер., 43 (12),1 (2007).

[13] А.Г. Кязым-заде, А.А. Агаева, В.М. Салманов, А.Г. Мохтари. ЖТФ, 7 (4), 80(2007).

[14] В.М. Салманов, И.А. Мамедбейли, Э.К. Гусейнов, А.А. Агаева. Приборы и техника эксперимента, 6, 130 (1996).

[15] M. Kalafi, H. Bidadi, H. Tajalli, V.M. Salmanov. Opt. Mater, 6, 117 (1996).

[16] Y.I. Ding, W. Shi. J. Nonlinear. Opt. Phys. Mater., 12 (4), 557 (2003).

[17] А.Г. Кязым-заде, В.М. Салманов, А.Г. Мохтари, В.В. Дадашова, А.А. Агаева. ФТП, 42 (5), 532 (2008).

[18] A. Frova, Ph. Schmid, A. Grisel, F. Levy. Sol. St. Commun., 23, 45 (1977).

[19] V.D. Egorov, G.O. M“uller, R. Zimmermann. Sol. St. Commun., 38, 271 (1981).

[20] C. Benoit a la Guillaume, J.-M. Debever, F. Salvan. Phys. Rev., 177 (2), 567 (1969). 